\title{
Ovarian ectopic pregnancy
}

\author{
Przemyslaw Szadok, Filip Kubiaczyk, Aleksandra Bajorek, Slawomir Suchocki
}

\section{E. Biernackiego Obstetrics and Gynecology Hospital, Walbrzych, Poland}

A twenty-eight-year-old female patient during the second pregnancy, about $6 \mathrm{hbd}$ (according to the date of the last menstrual period) from the spontaneous cycle, was directed to the local hospital because of suspected ectopic pregnancy with the location of the fallopian tube on the left side. She had no symptoms and vital parameters were in normal range. It was revealed that three years ago ectopic pregnancy of the right uterine tubule ended with right fallopian tube removal.

The result of the ultrasound examination performed during admission to the hospital confirmed the presence of a structure indicating to the ectopic pregnancy on the left side, moreover the picture of the uterus and right appendages without changes; a trace of fluid in the uterine cavity. Laboratory tests reported: the concentration of chorionic gonadotropin (HCG) was about $2530 \mathrm{mlU} / \mathrm{mL}$, blood count without deviation from the norm - HGB $12.8 \mathrm{~g} / \mathrm{dL}, \mathrm{HCT} 37.9 \%, \mathrm{RBC} 4.56 \mathrm{M} / \mu \mathrm{L}$.

During the diagnostic process, which lasted about 45 minutes, the general condition of the patient began to deteriorate. The following symptoms appeared: severe lower abdominal pain and nausea.

The study foundthat the entire lower abdomen together with the reproductive organ was painful during palpation, tenderness within the Douglas sinus, peritoneal symptoms +/-; increased muscle defense. RR 110/70 mmHg, HR approx. $95 / \mathrm{min}$. Urgent blood counts and bedside ultrasound were performed. The ultrasound imaging disclosed increased volume of fluid content in the utero-rectal cavity, morphology suggested hemorrhagic anemia - HGB $10.9 \mathrm{~g} / \mathrm{dL}, \mathrm{HCT}$ $33.1 \%, \mathrm{RBC} 3.84 \mathrm{M} / \mu \mathrm{L}$.

Due to the overall condition, the patient was qualified for immediate surgery due to suspected ectopic pregnancy rupture. Blood products were secured. After obtaining the informed consent of the patient, the surgery was started immediately. The abdominal cavity was opened using the Pfannenstiel method. Approximately $600 \mathrm{~mL}$ of blood, with clots, was found in the peritoneal cavity which was aspirated. The reproductive organ was assessed: endometrium unchanged. No fal-

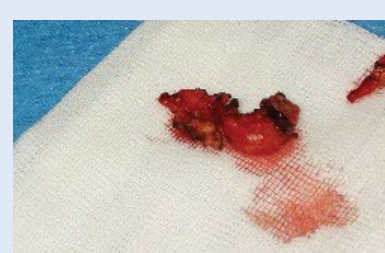

Figure 1. Removed part

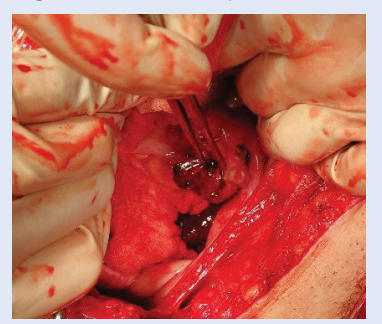

Figure 2. Laparotomy view

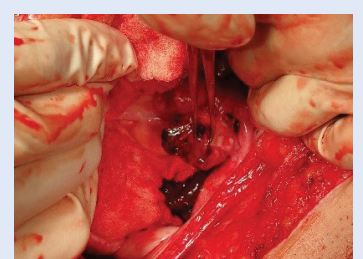

Figure 3. Laparotomy view

\section{REFERENCES:}

1. Kubiaczyk F, Suchocki S, Puskarz R, et al. [Bilateral tubal ectopic pregnancy in a spontaneous cycle--a case report]. Ginekol Pol. 2014; 85(8): 633-634, doi: 10.17772/gp/1785, indexed in Pubmed: 25219147.

2. Lin EP, Bhatt S, Dogra VS. Diagnostic clues to ectopic pregnancy. Radiographics. 2008; 28(6): 1661-1671, doi: 10.1148/rg.286085506, indexed in Pubmed: 18936028.

3. Nwanodi O, Khulpateea N. The preoperative diagnosis of primary ovarian pregnancy. Natl Med Assoc. 2006; 98(5): 796-798. be considered as well. lopian tube on the right side, the left fallopian tube unchanged. The right ovary unchanged, the left ovary cracked about $10 \mathrm{~mm}$ long with a change of about $20 \times 15 \mathrm{~mm}$ - trophoblast; severely bleeding. Wedge resection of the changed ovary and trophoblast was performed and the ovary was stapled. The material was sent for histopathological examination. After the abdominal cleaning, layered reconstruction of the coating was performer (Fig. 1-3).

Uncomplicated postoperative period. The patient did not require a transfusion of blood products. The morphology was unchanged comparing to preoperative period, chorionic gonadotropin concentration on "0" day after surgery about $1300 \mathrm{mlU} / \mathrm{mL}$. Discharge with recommendations on the 4th day after surgery - good general condition, no symptoms.

The result of the histopathological examination of the material: in the material a fragment of the cortical part of the ovary with a bloody corpus luteum cyst was found and among the blood clots a fetal ovum weaving - ectopic pregnancy. After receiving ult, the patient remains under care of a hospital gynecological outpatient clinic The examination after 4 and 12 weeks after surgery confirmed satisfactory conditions. Incorrect implantation accounts for $0.5-2.0 \%$ of all pregnancies [1]. In the case of ovarian pregnancy, the ovum is not released. Therefore it is not captured after ovulation but is fertilized in the ovary and implanted there [2]. As few as $0.15-3 \%$ of ectopic pregnancies nest in the ovary, which means this disease affects between 1:3000 and 1:7000 pregnancies $[3,4]$. The duration of such pregnancy may be up to 4 weeks, which may cause fatal intra-abdominal bleeding. The average period of their pregnancy was 45 days [5]. Due to the rarity of this type of pathology, as well as the danger of their complications - including the death, early diagnosis and treatment are crutial.

Selection of treatment method - pharmacological treatment or surgery, preferably sparing, should be taken individually. The patients clinical condition, the results of additional tests, as well as her obstetric history and the desire for further procreation should

Corresponding author:

E. Biernackiego Obstetrics and Gynecology Hospital, 10 Paderewskiego St, 58-301 Walbrzych, Poland

e-mail:p.szadok@mp.pl 